\title{
El talante espiritual de Descartes
}

\section{The Spiritual Disposition of Descartes}

\author{
Francisco de Jesús Ángeles Cerón \\ Universidad Autónoma de Querétaro, México \\ fangelesceron@gmail.com \\ Recibido: 20/01/2015 • Aceptado: 14/01/2016
}

\begin{abstract}
Resumen
Este trabajo inquiere sobre la posición de la religiosidad en la vida y obra de quien ha sido tenido por padre de la filosofía moderna, René Descartes. Entre otras cosas, se discute cuál es la relación entre el cristianismo heredado por Descartes y su sistema filosófico, así como si la de Descartes es la ética de un ateo o la de un creyente, apostando por una ética más provisoria que provisional. El autor intenta desenmascarar la posición del escritor de las Meditaciones metafísicas, aportando argumentos para sostener que la de Cartesio es la obra de un filósofo cristiano; la discusión sigue adelante realizando ulteriores distinciones entre el catolicismo y el protestantismo. Asimismo, se tratan los sentimientos característicos de la vivencia de una y otra confesiones de fe: angustia y confianza, para, finalmente, caracterizar la posición adoptada por Descartes. El análisis se apoya en los estudios histórico críticos actualmente disponibles sobre el pensador francés y enfatiza el valor de su epistolario en la correcta lectura de su obra.
\end{abstract}

Palabras clave: confianza, Descartes, ética de provisión, fe, razón.

\section{Abstract}

This paper inquires the position on religiosity of Rene Descartes life and works. Among other things, the author discusses the relation between the Christianism inherited by Descartes and his philosophical system, as well as the question of wether his Ethics are those of an atheist or those of a Christian, discussion where Ángeles thinks of «Ethics of provision», even more than «provisional Ethics». He tries to unmask the position defended 
by the writer of the Metaphisical Mediations, inclining towards the affirmation of Descartes works as those by a Christian. The discussion follows with ulterior distinctions on Catholicism and Protestantism, as well as their characteristical feelings: anguish and trust, to finally characterize Descartes position on religion. This analysis is supported in the historic and the critical analysis on the french thinker and is emphatic in stating the importance of the correspondence in the correct approach to his works.

Keywords: Descartes, Ethics of provision, faith, reason, trust. 


\section{“La maxime que j'ai le plus observée en toute la conduite de ma vie a été de suivre seulement le grand chemin, et de croire que la principale finesse est de ne vouloir point du tout user de finesse".}

Descartes a Elisabeth, enero de 1646.

Cuando la Historia de la Filosofía abre las puertas de su Corte a René Descartes, suele hacerlo mientras lo invita a un baile al que hay que asistir con máscara de por medio. Desde Maxime Leroy hasta, cuando menos, Jean-Luc Nancy, pareciera que si se quiere saber algo de Descartes es menester retirar de su rostro la máscara que ostenta. De todas las máscaras atribuidas al autor de las Meditaciones, la de la religión es, quizá, la que suscita mayor interés: ${ }^{1}$ la religiosidad de Descartes es un asunto que, desde donde se lo quiera ver, resulta tan atractivo como polémico, lo mismo al interior de los estudios cartesianos como hacia su exterior y deviene un asunto capital, incluso allende los terrenos de la filosofía moderna. Las razones para que esto resulte así pueden ser distintas. Pero es claro que la concepción y la relación que guarda el cartesianismo con el cristianismo atañe lo mismo a su epistemología que a su metafísica y a su moral. En ello estriba, esencialmente, la manera en la que Cartesio habrá de considerar, tanto a nivel gnoseológico como existencial, el modo en que se vinculan razón y fe, así como las consecuencias que esa relación tiene al interior de su sistema y todo cuanto éste hereda a la tradición.

Por ello, en un momento en el que la razón parece sucumbir ante un mundo que rechaza la fe al mismo tiempo en que es ramplonamente crédulo, es lícito volver una vez más hasta la figura de Descartes, pues el discípulo de los jesuitas en La Flèche es, en muchos sentidos, el pensador de gozne o de frontera en varias de las fracturas de su tiempo conceptuales, filosóficas y antropológicas de

1 Las deudas de Letras también se pagan. Inscribo este trabajo en la línea de investigación de los estudios cartesianos abierta en México por Juan Carlos Moreno Romo. A él, mi agradecimiento por ayudarme a ver a un Descartes que puede prescindir de sus máscaras. 
su tiempo. De ahí que no resulte baladí preguntarnos por qué a últimas fechas la espiritualidad de Descartes despierta tanto interés, así como también esclarecer algunos puntos tradicionalmente controversiales en las concepciones de fe y razón que sostiene el también autor del Discurso.

Por un lado, la afirmación que hace Descartes en la célebre "Carta a Voetius" (Ad celeberrimum virum D. GisbertumVoetium), de marzo de 1643, según la cual la caridad es "la base y el fundamento de todas las virtudes" (AT VIII-B: 111), ${ }^{2}$ podría hacernos suponer que para construir una defensa de su sistema frente a quien había impugnado su filosofía, recurre a los fundamentos de la religión cristiana (como podemos observar en varios pasajes de la extensa carta). Por lo que entonces, al referirnos a Descartes, tendríamos que hacerlo considerándolo como un filósofo que, al amparo del cristianismo y en estrecha relación con éste, habría construido la totalidad de su obra (o al menos lo que publicó en el transcurso de su vida). Pero, por otro lado, cuando alguien con la autoridad probada de Martial Gueroult afirma en una de sus obras esenciales sobre Descartes, tras analizar la moral del autor del Discurso, que precisamente "la moral de Descartes es la de un ateo" (Gueroult, 1953: 236), entonces ya no podemos dejar de confrontar la primera impresión que tenemos acerca de la religiosidad del filósofo francés.

Denis Kambouchner, fino conocedor de Descartes y profesor de Historia de la Filosofía Moderna en La Sorbona, sugiere en un profundo estudio que dedica al problema de la fe «en» $\mathrm{y}$ «de» Descartes, que el problema de la religiosidad del Caballero de la Turena bien puede plantearse mediante la forma de una antinomia: “ ¿Descartes fue un verdadero cristiano o fue un libertino enmascarado?” (Kambouchner, 2008: 254). Sin embargo, podríamos ir incluso más lejos de lo que propone este gran estudioso del pensamiento cartesiano. Una respuesta afirmativa acerca de la veracidad del cristianismo de Descartes implicaría preguntarnos qué tipo de cristiano fue, ya que cuando se lo ha llegado a asumir como tal, ni sus contemporáneos

2 Se citan tanto la versión de Adam Tannery como la de Alquie, donde sea el caso separando las referencias a cada edición de la obra cartesiana mediante el signo "/". 
(sea el caso de Pascal, por ejemplo), ni sus principales lectores anglosajones de nuestro tiempo (Watson, Shorto y Grayling, por citar algunos) parecen estar hablando del mismo cristiano.

Jean-Luc Nancy nos recuerda que, desde que los lectores de Descartes se concentraron cada vez más en la ahora tan conocida frase "Larvatus prodeo" (Descartes, AT I: 45) de los Preámbulos, muchos de ellos se precipitaron con demasiada confianza a levantar la «máscara» de Cartesio sin saber de dónde tomarla. Mientras tanto, otros lectores se propusieron encontrarla, pero en ambos casos a través de un ejercicio hermenéutico aparentemente interminable, se esforzaron por forjar a su «Descartes secreto» -no olvidemos como ejemplo reciente de ello, el libro del matemático Amir Aczel, que publicó en 2011 bajo el título El libro secreto de Descartes, y en el que no hace más que concentrarse en los textos que la mayoría de los lectores de este filósofo conoce como "los primeros pensamientos de Descartes", utilizando la frase acuñada por Gouhier. Jean-Luc Nancy subraya que en nuestro tiempo se hacen no menos y trabajosos esfuerzos por "fingir al verdadero Descartes" (Nancy, 2007: 47). Desde aquí es desde donde podemos afirmar que acercarnos al problema del talante espiritual de René Descartes - por lo que señalan Denis Kambouchner y Jean-Luc Nancy- representa un peligro inminente de caer en la trampa de pretender levantar su máscara. Es un peligro que habrá que sortear con cautela.

Denis Kambouchner señala que la oposición entre la comprensión apologética y la racionalista del cartesianismo, que refuerza entre otros Maxime Leroy, es el dedo índice que señala la historia misma de esta controversia, y es que a su interior cabe advertir varios episodios, entre los que se pueden contar: las acusaciones de impiedad por parte de los calvinistas de Utrech, el acento que jansenistas y oratorianos pusieron en la relación de Descartes con el agustinismo, la reivindicación de un cierto cartesianismo por parte de las Luces (d'Alambert) y los intentos de algunos autores del siglo XIX por postular una versión espiritualista del pretendido espíritu cartesiano. ${ }^{3}$

3 D. Kambouchner remite (en relación a la oposición en primer lugar aquí signada) al famoso libro de Maxime Leroy, Descartes, le philosophe au masque, al que nosotros 
Difícilmente podría ser otra manera. Cuando el filósofo francés aborda asuntos que tocan la religión en sus obras más importantes (en las Meditaciones, las Objeciones y Respuestas, el Discurso del método y los Principia, por ejemplo, si nos contentamos con citar sólo las más conocidas), además de que este punto ocupa sendas líneas de las cartas más difundidas en su Correspondencia. Es claro, pues, que el centro del pensamiento cartesiano, en lo que al asunto fundamental de la religión se refiere, es el lugar y la función que guardan las demostraciones de la existencia de Dios en su pensamiento. Por una parte, se aduce en ellas no más que un artificio técnico, de mera «técnica filosófica», dice Kambouchner — como podría ser justamente el caso de Pascal, quien con toda claridad expone esa discrepancia con el pensamiento cartesiano en el atribuido fragmento $1001-,{ }^{4}$ y por otra el teatro mediante el cual Cartesio expone una auténtica experiencia intelectual que da lugar a la meditación, intemporalmente. De un lado, entonces, se ve un acto de conveniencia nada más en los actos de sumisión pública a la Iglesia de Roma por parte de Descartes (Ricci, 1937: 100-101) y, de otro, se ve en ello un elemento definitorio en la constitución de su proyecto (Kambouchner, 2008: 255).

Por ello, ante el hecho real de que no hay en toda la obra de Descartes una exposición sistemática en materia de religión, se impone la reconstrucción de la religiosidad de Descartes a partir de sus propios textos. Intentaré, por tanto, no atribuir al francés un pensamiento que no esté presente en ellos, sin olvidar, no obstante, la pregunta por el talante o trasfondo espiritual del discípulo de los jesuitas de la Flèche, que es la pista o brújula que, para la lectura de este asunto, hemos tomado de José Luis L. Aranguren (Aranguren, 1998: 7 s.) y que Juan Carlos Moreno Romo ha traído a los estudios cartesianos. Ya en su momento, un muy serio y agudo especialista en

hemos hecho referencia también en este trabajo ; al mismo tiempo que subraya el gran trabajo de reconstrucción histórica de la relación entre Descartes y Francia que hace en su magistral Descartes et la France, François Azouvi (2008: 254-255).

4 Designaré los fragmentos que constituyen los Pensamientos de Pascal según los números correspondientes a las ediciones de Louis Lafuma y León Brunschvicg, unidos por un guión, justamente en ese orden. Traduzco a partir de la edición de las OEuvres complètes de Blaise Pascal hecha por de Seuil (1963). 
Descartes como Henri Gouhier, señaló oportunamente la importancia de tal relación.

En el autor de La pensée religieuse de Descartes podemos leer: “Todos esos detalles, se dirá -afirmaba refiriéndose al horizonte existencial de la religiosidad cartesiana-, carecen de importancia; lo esencial no es conocer la personalidad de Descartes, sino comprender su sistema; sólo que resulta que son dos cosas inseparables y que lo que en el fondo está en juego aquí es la interpretación total del cartesianismo" (Gouhier, 1924: p.11). Con todo y que Jean Laporte subrayara no mucho tiempo después de aquello, al interior de su monumental obra Le rationalisme de Descartes, que la cuestión de la religión en los textos y la vida de Cartesio sería un asunto necesariamente supeditado a la sinceridad de nuestro autor, declarando además la imposibilidad de «buscar en su corazón» (Laporte, 1945: 299-300).

¿Cuál es, pues, el trasfondo espiritual, o el talante -como diría Aranguren-desde el cual Descartes efectúa, defiende y promueve la aventura filosófica que, con la duda metódica como punta de lanza, supone la construcción de su obra entera? La pregunta es legítima tanto en el interés que suscitó el asunto entre sus contemporáneos -y muy especialmente en el antagonismo de Pascal-, como por la fuerte recuperación que desde horizontes diversos se hace en nuestros días respecto a varios elementos que constituyen, al parecer de muchos, la médula de su más aventajado pensamiento.

Una respuesta a la cuestión recién planteada, o un primer atisbo de ello, al menos, podemos encontrarlo gracias a la agudeza de Denis Kambouchner, quien señala como un texto capital a este respecto, un fragmento de las Respuestas a las «Segundas objeciones», específicamente, en lo tocante al quinto punto (Kambouchner, 2008: 259 s.). Ahí, Descartes intenta responder cómo es posible abrazar la fe en el momento en el que todo es obscuro y confuso, sin contravenir por ello la regla general de las Meditaciones, que sugiere que la voluntad debe alejarse del peligro de ser inducida al error hasta que siga las luces claras y distintas del espíritu, pues es esta una de las objeciones más complicadas que, en relación al gozne entre razón y fe le hacen 
a Cartesio en las Segundas objeciones recogidas por Mersenne (Descartes, $A T, I X: 100 ; A T, I I: 571-574)$.

El profesor Kambouchner señala que, lo primero que se impone en la respuesta de Descartes es la distinción entre el objeto al que se adhiere la voluntad, y la «razón formal» por la cual se inclina a asentir pues, si bien es cierto que la fe tiene por objeto «cosas obscuras», la razón se tiene por la que creemos estas cosas no es siempre obscura, sino que antes bien, la fe es -dice en las Segundas respuestas - "más clara que toda la luz natural" (Descartes, $A T, I X: 115$; Al, II: 572). Estamos hablando, pues, de obscuridad en la materia que puede ser compatible con la claridad de la razón. Por ello, un poco más delante de donde Descartes hace esta distinción, el Caballero de la Turena señala que la claridad por la cual nuestra voluntad se ve llamada a asentir, puede tener dos orígenes distintos, a saber: uno es la luz natural, únicamente, y otro es la gracia divina ( $A T, I X: 116$; Al, II: 573). ¿En qué consiste, entonces, la «razón formal» de la fe? La explicación que de ello ofrece Descartes, todavía en las Segundas repuestas, es significativa sobre todo por lo ortodoxa que resulta en relación con los postulados de la Iglesia romana (o a la filosofía tomista, más específicamente). Así, en el citado texto, Cartesio escribe que aquella «razón formal» de la fe consiste:

en una cierta luz interior con la que Dios nos ilumina de un modo sobrenatural, y gracias a ella confiamos en que las cosas propuestas a nuestra creencia nos han sido reveladas por Él, siendo enteramente imposible que mienta y nos engañe: lo cual es más seguro que cualquier otra luz natural, hasta, a menudo, más evidente, a causa de la luz de la gracia (Descartes, $A T, I X: 116$ / Al, II: 574).

Para Descartes está claro, entonces, que si Dios nos hace ver que Él nos revela todo cuanto nos revela, y por ello no es un Dios tramposo o mentiroso, estamos, pues, con la que sería necesariamente la primera verdad metafísica que, al ser trascendentalmente cierta, precede a todas las verdades y conocimientos (Kambouchner, 2008: 
261), tal como habrá de asentarlo una vez más Descartes en las Sextas repuestas (Descartes, AT, IX: 230 / Al, II, 868).

Denis Kambouchner considera necesario subrayar que, respecto a un punto sumamente complicado, el desarrollo cartesiano goza, no obstante, de una «gran tranquilidad», lo cual nos conduce a la delicada distinción que Cartesio hace en la "Carta a Hyperaspistes", de agosto de 1641, donde aclara que él no sostiene que por la luz de la gracia podamos conocer los misterios de la fe (aunque tampoco niega que sea posible), puesto que él no ha defendido que mediante la luz de la gracia nosotros creamos lo que creemos, sino solamente que aquella nos hace conocer muy claramente que es necesario creer (Descartes, AT, III: 426 / Al, II: 363-364). Pero, además de situarnos en la aguda diferencia que en la citada carta establece Descartes, la tranquilidad de la que habla Kambouchner en relación a la manera en la que el cartesianismo aborda los asuntos relacionados con la fe también nos hace pensar en la tesis sostenida por Juan Carlos Moreno Romo en su Vindicación del cartesianismo radical, donde señala que es la moral cartesiana el punto clave a analizar si se quiere comprender en toda su dimensión existencial el estatuto que la fe guarda en Descartes (Moreno Romo, 2011: 157 s.).

El comienzo de la tercera parte del Discurso del método puede sonar, en primer término, a una suerte de contrapeso que para algunos podría resultar acaso un freno al entusiasmo inicial con el que el proyecto cartesiano es identificado al inicio de la "Meditación primera", es decir: con el objetivo de "empezar todo de nuevo desde los fundamentos" (Descartes, $A T, I X: 13$ / Al, II, 404) y que lleva a Descartes, al final de la misma, a "suspender el juicio" (Descartes, AT, IX: 18 / Al, II, 412). La razón fundamental de este paso descansa, esencialmente, en el hecho de que, si bien la empresa cartesiana es -a diferencia de los Ejercicios espirituales de san Ignacio--, una meditación gnoseológica, ésta no puede ignorar que se lleva a cabo dentro de una dimensión existencial, lo cual marca una pauta diferente a las especulaciones reflexivas que el Caballero de la Turena realiza y deja al cartesianismo muy lejos de poder ser considerado como un procedimiento de aislamiento dubitativo estrictamente hablando. 
Por el contrario, aunque la imagen del árbol del conocimiento con la que el propio Cartesio pretende ofrecernos un diseño de la totalidad de su filosofía, nos presenta a la moral (junto a la medicina y la mecánica) como las principales ramas que surgen de aquel tronco de la física que se levanta desde las raíces de la metafísica (Descartes, $A T, I X-B: 14$ ) y la moral es considerada, por ello, como la máxima expresión de la sabiduría en Descartes, no quiere decir, por ello, que con aquella famosa imagen, el autor de las Meditaciones esté trasladando la moral a un plano que estaría completamente alejado de la vida práctica. Por estar aquella ligada al problema de la certeza, tan inherente, inevitablemente, al asunto de la sabiduría.

El mismo Cartesio, distinguiendo lo anterior, va a escribir en aquella exposición escolar de su filosofía que pretendía que fueran los Principia, que

con el fin de evitar todo prejuicio a la verdad, suponiéndola menos cierta de lo que es, distinguiré dos tipos de certezas. La primera es denominada moral, es decir, suficiente para regular nuestras costumbres, o tan grande como la que tenemos acerca de las cosas de las que no tenemos costumbre de dudar en relación con la conducta de la vida, aun cuando sepamos que puede ser que, absolutamente hablando, sean falsas [...] La otra clase de certeza es la que tenemos cuando pensamos que no es en modo alguno posible que la cosa sea de otra forma a como la juzgamos. Esta certeza está fundamentada sobre un principio de la Metafísica muy asegurado y que afirma que, siendo Dios el soberano bien y la fuente de toda verdad, puesto que él es quien nos ha creado, es cierto que el poder o la facultad que nos ha otorgado para distinguir lo verdadero de lo falso, no se equivoca cuando hacemos un uso correcto de la misma y nos muestra evidentemente que una cosa es verdadera (Descartes, $A T, I X-2$ : 323-325).

Esto quiere decir que, para Descartes, en la vida práctica el hombre sólo cuenta con certezas morales para poder actuar, para poder determinarse. Es precisamente en las primeras líneas de la Tercera 
parte del Discurso donde el filósofo francés va a señalar con mayor precisión que las certezas morales están constituidas por opiniones prudentes, de las que no se puede prescindir hasta tener otras mejores, por lo que, si algo hay que evitar es la precipitación (Descartes, AT,VI: 17 / Al, I: 585). Aún hay más: el centro de la prudencia que Cartesio señala en los Principios como la regla de la certeza moral, está detalladamente presentada en esa sucinta y no obstante profunda descripción de la moral par provisión en el Discurso. Juan Carlos Moreno Romo y Geneviève Rodis-Lewis nos animan a traducir «Moral de provisión» y no «moral provisional», poniendo el acento en la diferencia que existe entre «provisionnelle» $\mathrm{y}$ «provisoire» (Moreno Romo, 2011: 28, n. 12; Rodis-Lewis, 1995: 288), pues parece ser, justamente, refugio, cobijo y sustento lo que representan para el proyecto en su totalidad, las "tres o cuatro máximas" (Descartes, $A T, V I: 22$ / Al, I: 592) de las que se compone la moral expuesta tan significativamente en un momento inmediatamente posterior a la exposición del método y justo antes del desarrollo de la duda hiperbólica. Así lo confirma la introducción a la descripción de aquellas máximas en donde Cartesio escribe:

Finalmente, como antes de comenzar a reconstruir la casa en la que habitamos no es suficiente destruirla y hacer provisión de materiales y de arquitectos, o ejercitarse uno mismo en la arquitectura, y haber trazado además cuidadosamente los planos, sino que es necesario también haberse provisto de otra, donde uno puede vivir cómodamente durante el tiempo de los trabajos; así, para no quedarme irresoluto en mis acciones mientras la razón me obligase en mis juicios, y no dejar por ello de vivir lo más feliz que pudiera, me formé una moral de provisión (Descartes, AT,VI: 22 / Al, I: 591-592).

El autor de las Meditaciones seguirá - nos anuncia en el Discursolas costumbres del lugar en donde se halle, permaneciendo firme, eso sí, en la religión que fue la de sus padres y en la que Dios le concedió la gracia de haberse formado, mientras que, en la vida pública, de manera muy especial, habrá de seguir las costumbres más 
moderadas, apartándose de todo extremo que pudiera exponerlo en demasía; así como también, por otro lado, una vez tomada una decisión, actuará con firmeza, tenacidad y sin vacilamientos; y procurará, finalmente, no pretender cambiar el rumbo del mundo sino, antes bien, vencerse a sí mismo antes que a la fortuna (Descartes, $A T$, VI: 23-28 / Al, I: 592-598).

Para el tema que aquí nos ocupa, que es el de aclarar cuál sea el talante o trasfondo espiritual de Descartes y, por ende, de su empresa filosófica, es la primera de las máximas la que mayor interés adquiere, puesto que al enunciar la intención de,

obedecer las leyes y costumbres de mi país, manteniendo con firmeza la religión en la que Dios me concedió la gracia de ser instruido desde mi infancia, y gobernándome en todo siguiendo las opiniones más moderadas y más alejadas del exceso, que fuesen comúnmente recibidas en la práctica por los más sensatos entre aquellos con quienes tendría que vivir (Descartes, AT, VI: 23 / Al, I: 592-593).

El discípulo de los jesuitas de la Flèche está concediendo que la Revelación, lo mismo que la autoridad de la Iglesia, puedan ser fuente de verdad y, sobre todo, refugio existencial, por más que fuese posible en lo sucesivo alcanzar claridad por medio de la luz natural de la razón.

El propio Henri Gouhier ha expresado la íntima relación que Descartes tejió entre metafísica, moral y propedéutica a la religión. Así, el profesor francés escribe en La pensé religeuse de Descartes, que "no podemos decir que Descartes haya encontrado en la metafísica una simple introducción a la ciencia: la cultiva en principio por ella misma y no deja de ver en ella una introducción a la religión" (Gouhier, 1924: 181). Esto lo apuntaba Gouhier, a propósito de un intento por explicar cómo es que del famoso árbol de la ciencia cartesiana emerge la rama dedicada a esa "moral más alta y perfecta, que, presuponiendo un conocimiento completo de las otras ciencias, es el último grado de la sabiduría" (Descartes, $A T, I X-B: 14$ ) y de la cual habla Cartesio en la "Carta a Picot". Sin duda, el lugar que en la filosofía mecanicista de 
Descartes tendría en realidad la moral ha sido siempre asunto polémico, así como también ha generado disputas el modo en el que se construiría la pretendida moral definitiva en el pensamiento cartesiano.

Antonio Marino, por ejemplo, ha subrayado que el sabio cartesiano sólo es posible si la ciencia fisicomatemática y la moral aseguran el dominio de la pasión. Esto es factible únicamente si la comunicación de las substancias a este respecto es tal que el poder de la mente pueda establecer dominio sobre el cuerpo y viceversa. Así, Antonio Marino concibe la moral cartesiana como el antecedente y la fortaleza conceptual de la bioingeniería moral (Marino López, 2007: 203 s.). Ello supondría, entonces, que desde esta perspectiva la moral habría sido colocada en la cumbre del proyecto cartesiano no tanto porque ésta responda a una necesidad existencial como porque representa una posibilidad de la ciencia.

Sin embargo, aunque no compartimos con Antonio Marino el hecho de ubicar a Descartes en ese proceso de entronización del hombre que, generando su propio modo de entender la posibilidad de alcanzar una autarquía habría de convertirse en el señor de todo, sí convenimos con él en que la moral, al contrario de lo que piensa Jaspers, sí ocupa un lugar que se deriva, todo él, de los principios y la filosofía planeada por Descartes (Jaspers, 1973: 94 s.), pues para afirmar lo que el agudo e intenso pensador alemán señala de la moral cartesiana, habría que asumir que el todo de la filosofía de Cartesio está edificado fuera de la existencia misma, y que no responde, entonces, a indigencia alguna, lo cual, si hacemos caso a esa intrincada liana que une íntimamente la obra de Descartes con su discutida biografía, está muy lejos de poder parecernos cierto.

La correspondencia con Elisabeth de Bohemia y con Cristina de Suecia dará razón, precisamente, de que la moral cartesiana arraiga profundamente en una situación humana a la que el autor del Discurso pretende dar cauce de forma radical. Constantemente insistirá Descartes en que el fin último del hombre descansa en dar alcance a la perfección a través del ejercicio del libre albedrío (Descartes, $A T$, $I V: 305 ; A T, V: 82)$. Por ello, no podemos afirmar que el cartesianismo vea en el hedonismo de la Modernidad «consumada» la finalidad de su proyecto. Tampoco podríamos asentir a la afirmación de que 
la moral que construye Descartes sea agregado que no responde a una necesidad primigenia del proyecto de su pensamiento o que no emerge como respuesta a una cierta pobreza de certidumbre en relación a los asuntos de la vida diaria - sin llegar, no obstante, a publicar jamás un tratado dedicado a este asunto, que dejara del todo saldada su posición al respecto--.

Octave Hamelin supo condensar esta reflexión que aquí planteamos, al afirmar que, en Descartes, "el placer, siendo signo y efecto de la perfección, debe estimarse por su causa” (Hamelin, 1949: 379). El gran especialista subraya en Le système de Descartes que, en el centro de lo que se considera «la moral definitiva» contenida en las cartas a Elisabeth, persiste lo que el autor de las Meditaciones expuso en la moral de provisión, "pues aunque el género humano hubiera dado término a la tarea de la ciencia, siempre subsistiría para el individuo el deber de asimilársela" (Hamelin, 1949: 378). El propio Hamelin se pregunta si la ausencia de un tratado dedicado a la moral en la filosofía cartesiana se debe a que aquella no representaba un interés real para Cartesio, para responder que no: a su juicio, la verdad sobre el asunto es más simple, pues "Descartes tuvo el sentimiento pleno - dice el profesor francés- de que la última de las ciencias, aunque la más urgente, era también la más compleja: no se ocupó de ella porque no disponía del tiempo suficiente para elaborar su física y, menos aún, para terminar su mecánica y su medicina, que eran las primeras aplicaciones de la física" (Hamelin, 1949: 378).

El mismo autor del Discurso nos da una razón más para no componer un tratado sobre moral, pese a reconocer en la "Carta a Chanut del 1 de noviembre de 1646" que, de haberlo hecho, su obra le habría agradado aún más a la Reina de Suecia pues, dada la situación de censura que lo rodeaba y la reciente "Querella de Utrech", por ejemplo,

sería una imprudencia hacerlo -le dice en esa misma carta a Chanut-. Los Señores Regentes están tan en contra mío a causa de los inocentes principios de Física que han visto que, si después de eso tratara de la Moral, no me dejarían en paz. Si un P. Bourdin creyó encontrar motivo suficiente para acusarme de escepticismo, por mi afán de refutar a los escépticos, y si un 
Ministro se ha puesto a persuadir a la gente de que yo era ateo sin alegar más razón que mi intento de demostrar la existencia de Dios, ¿qué no dirían si yo tratara de examinar cuál es el valor justo de las cosas que pueden desearse o temerse, cuál será el estado del alma después de la muerte, hasta qué punto debe amarse la vida y cómo debemos ser para que no nos intimide la idea de perderla? En vano tendría yo las razones más conformes a la Religión y las más útiles posibles al bien del Estado; insistirían en hacerme creer que son contrarias tanto a una como a otro. Por eso, creo yo que lo mejor que puedo hacer de hoy en adelante es abstenerme de escribir libros y no comunicar mis pensamientos sino a aquellos con los que pueda conversar en privado (Descartes, $A T, I V: 536 \mathrm{~s}$.).

Aunque podría parecer mezquina la razón que da Descartes para abstenerse de abordar los asuntos concernientes a la moral, sin embargo como bien se ocupa de subrayar en la citada misiva a Chanut, supone que el solo intento le generaría conflicto, entre otras cosas, por hacer coincidir con el orden de la Revelación, el todo de sus reflexiones al respecto; y es quizá esa misma la razón por la cual la llamada «moral definitiva» quede solamente expresada en su correspondencia con Elisabeth y Cristina y que, como hemos visto, guarde en lo general la misma forma que la «moral provisoria» como prefiere llamar Hamelin a la exposición de la tercera parte del Discurso. Pues en tanto que era creyente, a Descartes parece no resultarle un enfado sino, por el contrario, un gusto, abandonar a la religión la dirección de la vida, muy lejos, entonces, de Spinoza, por ejemplo, ese primer gran moralista moderno sin confesión aparente, quien, a fuer de tallar conceptos se hizo un por qué geométrico que respondiera esas vicisitudes diarias que tiene la vida (Hamelin, 1949: 383), aunque esta postura se encuentra también muy lejos de Pascal, para quien la meditación sobre la muerte, el dolor y la indigencia humana, la pequeñez de nuestra naturaleza y el abismal infinito en medio del cual se encuentra el hombre impedían tener tranquilidad ninguna en ese aspecto, hasta llevarle a escribir a manera de summa sobre aquel sentimiento, que: 
Todo este mundo visible no es más que un trazo imperceptible en el amplio seno de la naturaleza. No hay idea que se le aproxime. En vano hinchamos nuestras concepciones, más allá de los espacios imaginables; sólo engendramos átomos, en comparación con la realidad de las cosas. Es una esfera cuyo centro está en todas partes, cuya circunferencia no está en ninguna. En fin, es la mayor señal de la omnipotencia de Dios, que nuestra imaginación se pierda en ese pensamiento (Pensamientos: 199-72a).

En muchos sentidos, en este pasaje suena ya la desesperación desde la que escriben Kierkegaard, Jaspers e, incluso, Karl Barth, quienes indefectiblemente se asemejan en ello por completo a Lutero, a cuyo talante, como hemos visto en otra parte, se parece tanto el de Pascal. Borges ha sabido resumir con altísima precisión el sentimiento religioso pascaliano al decir que el autor de los Pensamientos

aborrecía el universo y hubiera querido adorar a Dios, pero Dios, para él, era menos real que el aborrecido universo. Deploró que no hablara el firmamento, comparó nuestra vida con la de náufragos en una isla desierta. Sintió el peso incesante del mundo físico, sintió vértigo, miedo y soledad (2000: 162).

En este pasaje no resulta difícil encontrar un «sentimiento trágico de la vida» - para usar la expresión unamuniana - nacido de un pathos muy lejano a la tranquilidad con la que Descartes afronta situaciones del mismo orden, tal como apuntaba en su estudio sobre el problema de la fe en Descartes, el profesor Denis Kambouchner (2008: 262), aunque la que más suele reclamar a Descartes no desesperar en el tránsito de la duda metódica y en todo ese ejercicio gnoseológico que relatan las Meditaciones es, precisamente, la tradición luterana en la que se inscriben Sören Kierkegaard, Karl Jaspers y Karl Barth, donde incluso habría que apuntar al «católico de talante protestante» que, a decir de José Luis L. Aranguren, sería Pascal. El gran filósofo de la existencia que fuera Karl Jaspers es contundente en su reproche al señalar que "Esa duda -refiriéndose a la duda metódica- no es la desesperación por medio de cuya crisis puede 
nacer la certeza de una verdad sobre la cual asiento mi vida" (Jaspers, 1973: 25). En efecto, el autor de La fe filosófica tiene razón: no es la desesperación el punto de partida ni mucho menos el puerto adonde ancla la aventura cartesiana.

La situación que circunda a la puesta en marcha de la duda dentro de las Meditaciones mismas, está en franca tensión con la actitud escéptica que Richard Popkin ha sabido exponer con oportuna claridad (Popkin, 1983: 259 s.), y es por ello que este momento fundamental de la aventura cartesiana, por un lado, pero también de la Modernidad completa, por otro, las preocupaciones de orden puramente espiritual o religiosas en el sentido más existencial del término, quedan abrazadas al interior de la primera de las máximas de las «moral de provisión», en la que Descartes entrega por entero a "la religión en la que Dios le ha hecho la gracia de ser instruido desde su infancia" (Descartes, AT,VI: 23 / Al, I: 592) la ocasión de aclararle la densa serie de problemas que en orden de lo existencial pudiera acarrear el poner en marcha el procedimiento de la duda hiperbólica. Se trata, pues, de una duda que no duda de la fe, en el sentido en que hemos querido exponerla desde los textos cartesianos más arriba expuestos. La duda metódica de Cartesio no es en efecto el abandono al abismo espiritual al que invita por ejemplo Lutero, quien, por donde queramos buscar, es el genio tutelar de las acusaciones al cartesianismo que hemos glosado aquí. Por el contrario, e incluso pese a Kierkegaard, Descartes prefiere distinguir entre teoría dubitante y praxis no dubitante, lo que al talante luterano del gran pensador danés no le parece consecuente. ${ }^{5}$

Aunque en Descartes no podría ser de otra manera, en tanto que el caballero francés insiste constantemente en la confianza (confidimus) que creer en Dios otorga. En efecto, la confianza es una noción recurrente no sólo en las Respuestas a las «Segundas Objeciones», sino, sobre todo, en lo que puede ser una suerte de adenda a aquellas, y que es la "Carta a Hyperaspistes de agosto de 1641" (Descartes, AT,

5 Hans Küng comenta la posición de Sören Kierkegaard (Johannes Climacus) en relación a la posibilidad de llevar a cabo radicalmente y a nivel existencial, la duda metódica de Descartes, sin apoyarse en seguridad alguna (2005). 
III: 426 / Al, II: 363), ya que aplica lo mismo a la Revelación que a la necesidad de creer, según sea el texto de que se trate, como subraya Denis Kambouchner (Kambouchner, 2008: 263), pues si es justamente esa confianza lo que la tradición de talante luterano le reprocha a Descartes en tanto que aquella supone un antídoto contra la desesperación - "tan cercana ella misma de la Gloria” (Lutero, 1988: 115), como dice Lutero-, entonces estamos también frente a una situación o trasfondo espiritual muy distinto en un caso y otro. Es precisamente la identificación de éste lo que nos permite comprender en «otra» dimensión, o en «toda» su dimensión, una posición filosófica determinada. Como escribe Aranguren: "Con la filosofía, con la buena filosofía, acontece [...] que reposa sobre un talante determinado y, a la vez, termina suscitándolo" (Aranguren, 1998: 14). El talante en el que reposa el cartesianismo y que al mismo tiempo suscita la lectura de Descartes es un ethos más propiamente católico. "No hay, pues, un único estado de ánimo apto para el conocimiento -subraya el propio Aranguren-, pero sí hay una jerarquía de estados de ánimo y, en lo alto de ella, están (buen talante): la esperanza, la confianza, la fe, la paz" $(1998,16)$.

La confianza es lo que sostiene, desde la «moral provisoria», la empresa cartesiana. Sólo se alcanza la confianza, antípoda de la desesperación, en un ethos espiritual que, alejado del «talante protestante» se halla sereno ante el irresoluble misterio de la salvación postrera-significativamente distanciado de las posibilidades de la razón, la gracia, que también tiene lugar en la carne, muy específicamente en la libre voluntad humana-, no está angustiado a ese respecto, tal como acontece en el «talante católico», en el que la comunidad es el auxilio y los sacramentos, muestra viva de que la gracia tiene lugar en y gracias a la naturaleza de la que surge la tan mencionada «Confianza», que también deja lugar a la razón, y no solamente a la fe. Como hacía notar Descartes en 1648, en un fragmento de las Observaciones sobre el Programa de Regius:

deben ser distinguidas tres clases de cuestiones: unas son creídas en virtud de la fe, como los misterios de la Encarnación, de la Trinidad y semejantes; las segundas, por el contrario, aunque 
conciernen a la fe, también pueden ser examinadas mediante la razón; los teólogos ortodoxos suelen enumerar entre éstas las relacionadas con la existencia de Dios y la distinción del cuerpo del alma. Finalmente, se da un tercer tipo de cuestiones que se relacionan únicamente con la razón humana, y de ninguna forma con la fe, como por ejemplo el problema de la cuadratura del círculo, la posibilidad de obtener oro por medio del arte químico y otras semejantes (Descartes, AT,VIII-B: 353).

Cabe señalar, entonces, que llevar a la razón a su máxima tensión en consonancia con las fuerzas del espíritu y mantener, no obstante, la tranquilidad que en ello se manifiesta, es posible en el cartesianismo gracias a lo que, a propósito de todo esto, se manifiesta: el catolicismo de Descartes que es, en sentido existencial, el trasfondo espiritual sobre el que descansa la gran aventura de la «luz natural de la razón» expuesta fundamentalmente en las Meditaciones, pero que, acompañada de aquella serenidad, va cruzando a galope el todo del sistema de Cartesio; un talante espiritual que se revela tanto más claro cuanto más férreos son los ataques que, desde el protestantismo, reciben la confianza y la serenidad con la que Descartes afronta los desafíos de la razón. Más aún careciendo de toda claridad, no se trata, desde luego, solamente de creer. Como expone el Caballero de la Turena en las Segundas Respuestas:

me atrevo a afirmar sin rodeos que un infiel desprovisto de toda gracia sobrenatural, y del todo ignorante de que han sido reveladas por Dios las cosas en que creemos «nosotros los cristianos», si, con todo, atraído por algún falso razonamiento, se inclinase a creer esas mismas cosas - que para él serían obscuras-, no por ello dejaría de ser infiel, sino que más bien pecaría al no usar de su razón como es debido (Descartes, $A T, I X: 16$ / Al, II, 574).

Tales son las condiciones del talante católico de René Descartes, quien, al concentrar en torno a su figura y justo en los albores de la Modernidad, buena parte de los clásicos problemas que suscitan las relaciones entre fe y razón, conduce también, como consecuencia, al 
hecho de que meditar sobre las dimensiones espirituales de la filosofía triunfante en la Modernidad «realizada» y en los enfrentamientos que se libran a propósito de la persona y la filosofía de quien quizá fuera en último gran filósofo de la frontera que separa al talante protestante del católico, no sea, pues, una cuestión baladí, sino que, por el contrario, sea un asunto que recobra especial importancia cuanto más nos aclara el panorama de la filosofía contemporánea. Si Pascal, en los Pensamientos, reprocha a Descartes el utilizar en demasía la razón (Pensamientos: 553-76) y, específicamente, en relación con asuntos en los que solo debería intervenir la fe, con mayor razón aun es que resulta imprescindible discutir cómo es posible entonces que tenga lugar aquello en el pensamiento de Cartesio y de qué modo ocurre que el tan traído y tan llevado "padre de la Modernidad" ofrece respuesta a ello.

Referencias bibliográficas

Aranguren, J.L.L. 1998. Catolicismo y protestantismo como formas de existencia. Madrid: Biblioteca Nueva.

Borges, J.L. 2000. "La esfera de Pascal”. En Nueva antología personal. México: Siglo XXI Editores.

Descartes, R. 1996. Oeuvres de Descartes. C. Adam, P. Tannery (eds.). París: Librairie Philosophique J. Vrin.

Gouhier, H. 1924. La pensée religieuse de Descartes. París: Vrin.

Gueroult, M. 1953. Descartes selon l'ordre de les raisons. París: Aubier.

Hamelin, O. 1949. El sistema de Descartes. AH Raggio, (ed.). Buenos Aires: Losada.

Jaspers, K. 1973. Descartes y la filosofía. Buenos Aires: La Pléyade.

Kambouchner, D. 2008. Descartes et la philosophie morale. París: Hermann Éditeurs.

Küng, H. 2005. ¿Existe Dios? Respuesta al problema de Dios en nuestro tiempo. JM Bravo Navalpotro (ed.). Madrid:Trotta.

Laporte, J. 1945. Le rationalisme de Descartes. París: PUF.

Lutero, M. 1988. Escritos reformistas de 1520 (A la nobleza cristiana de la nación alemana acerca del mejoramiento del Estado cristiano / La cautividad babilónica de la Iglesia / 
La libertad cristiana). H. Martínez (selecc., pról., notas). México: Secretaría de Educación Pública.

Marino López, A. 2007. "La metafísica de la generosidad cartesiana”. En JC Moreno Romo (coord.). Descartes vivo. Ejercicios de hermenéutica cartesiana. Barcelona: Anthropos/UAQ.

Moreno Romo, JC. 2011. Vindicación del cartesianismo radical. Barcelona: Anthropos.

Nancy, J.L. 2007. Ego sum. JC Moreno Romo (trad.). Barcelona: Anthropos-UAQ.

Pascal, B. 1963. OEuvres completes de Blaise Pascal. H. Gouhier (pról.), L. Lafuma (notas). París: Editions du Seuil.

Popkin, R.H. 1983. La historia del escepticismo desde Erasmo hasta Spinoza. México: Fondo de Cultura Económica.

Ricci, C. 1937. "Descartes y el problema religioso", En: JL Guerrero (ed.). Homenaje en el tercer centenario del Discurso del método, Vol. II. Buenos Aires: Universidad de Buenos Aires.

Rodis-Lewis, G. 1995. Descartes. Biographie. París: Calmann-Lévy. 